\title{
Chronic hypoxia increases peroxynitrite, MMP9 expression, and collagen accumulation in fetal guinea pig hearts
}

\author{
LaShauna C. Evans ${ }^{1}$, Hongshan Liu², Gerard A. Pinkas ${ }^{2}$ and Loren P. Thompson²
}

INTRODUCTION: Chronic hypoxia increases the expression of inducible nitric oxide synthase (iNOS) mRNA and protein levels in fetal guinea pig heart ventricles. Excessive generation of nitric oxide (NO) can induce nitrosative stress leading to the formation of peroxynitrite, which can upregulate the expression of matrix metalloproteinases (MMPs). This study tested the hypothesis that maternal hypoxia increases fetal cardiac MMP9 and collagen through peroxynitrite generation in fetal hearts.

RESULTS: In heart ventricles, levels of malondialdehyde, 3-nitrotyrosine (3-NT), MMP9, and collagen were increased in hypoxic (HPX) vs. normoxic (NMX) fetal guinea pigs.

DISCUSSION: Thus, maternal hypoxia induces oxidative-nitrosative stress and alters protein expression of the extracellular matrix (ECM) through upregulation of the iNOS pathway in fetal heart ventricles. This identifies iNOS-derived NO as an important stimulus for initiating the adverse effects of peroxynitrite in HPX fetal hearts.

METHODS: Pregnant guinea pigs were exposed to normoxia (room air) or hypoxia $\left(10.5 \% \mathrm{O}_{2}, 14 \mathrm{~d}\right.$ ) before term (term $\approx 65$ d) and administered water, L-N6-(1-iminoethyl)-lysine (LNIL), an iNOS inhibitor, or N-acetylcysteine (NAC), an antioxidant.

O ver the past decade, results of several studies have generated interest in the effects of intrauterine hypoxia on the fetal heart (1-7). This condition can result from several pregnancyrelated complications such as maternal illness, placental insufficiency, and living at high altitude, resulting in reduced oxygenation of the fetus (8-10). Prolonged exposure to a hypoxic (HPX) environment can result in intrauterine growth restriction, a leading cause of fetal morbidity and mortality (11), and organ-specific pathologies of the heart (e.g., myocardial hypertrophy) and brain (e.g., severe gliosis in the cerebral cortex and decreased myelination) $(11,12)$.

Chronic fetal hypoxia has been shown to alter heart-specific mechanisms associated with nitric oxide (NO) generation (1-3) as well as protein kinase C (13), ventricular growth (5), and energy metabolism (7). NO is generated by NO synthases (NOSs) in mammalian tissue (14) by two constitutive forms (endothelial (eNOS) and neuronal NOS) and one inducible form (iNOS) (14). In fetal guinea pigs, conditions of hypoxia upregulate iNOS (1) but downregulate eNOS mRNA/protein levels (2) in heart ventricles, identifying iNOS-derived NO synthesis as an important mechanism contributing to HPX stress. In addition, fetal hypoxia increases the generation of reactive oxygen species (15), and the interaction of NO and reactive oxygen species can lead to the formation of peroxynitrite (16), a potent cytotoxic molecule in cardiac tissue (16).

Chronic hypoxia can contribute to disruption of both cardiac structure and function (6). In adult hearts, peroxynitrite plays a key role in cardiac pathologies associated with ischemiareperfusion injury (16), myocardial contractile dysfunction (17), and heart failure (18). The role of peroxynitrite in HPX fetal hearts has not been investigated, but it is likely a key oxidant contributing to cardiac injury. Fetal cardiac pathology associated with peroxynitrite may have lasting consequences in the offspring and increase the risk for heart failure in the adult.

Peroxynitrite has been shown to stimulate the translocation of nuclear transcription factors (nuclear factor-kappa B and activator protein-1) to the matrix metalloproteinase (MMP) promoter site (19), thereby upregulating MMP expression. The MMP gene family consists of several protein subtypes contributing to the modulation of the extracellular matrix (ECM) (19), with MMP2 and MMP9 playing key roles in cardiac tissue $(19,20)$. Recent studies provide insight into the role of MMPs as modulators of the myocardial ECM in cardiac pathologies (e.g., heart failure (21), ischemia-reperfusion injury (21), and myocardial contractile dysfunction (20,22)). Upregulation of MMP expression and activation contributes to collagen degradation of the ECM in a time-dependent manner (20). With prolonged activation, collagen subfragments degraded by selective MMPs such as MMP2, MMP9, and MMP13 promote collagen synthesis by disrupting the balance between synthesis and degradation, resulting in collagen accumulation and cardiac fibrosis $(23,24)$.

This study examined the role of iNOS-derived NO in mediating the formation of peroxynitrite in fetal guinea pig hearts of normoxic (NMX) and HPX animals. We measured lipid peroxidation, as an index of oxidative stress, and protein-associated 3-nitrotyrosine (3-NT) levels, as an index of peroxynitrite formation. In addition, fetal cardiac MMP9 expression and collagen accumulation were measured as downstream actions of peroxynitrite formation. A selective competitive inhibitor of iNOS activity, L-N6-(1-iminoethyl)-lysine (LNIL), and N-acetylcysteine 
(NAC), an endogenous glutathione precursor and antioxidant, were administered to pregnant sows to determine the roles of iNOS-derived NO and oxidative stress, respectively, as modulating factors of the ECM in HPX fetal hearts.

\section{RESULTS}

\section{Effect of Hypoxia on Fetal Body and Organ Weights}

Chronic hypoxia caused a decrease in fetal guinea pig body weight of $19 \%$ (Table 1) associated with an increase in relative (normalized to fetal body weight) placental, heart, and brain weights, but not relative liver weight. LNIL reduced fetal body weight of NMX (19\%) but not HPX animals. NAC reduced body weight of both NMX (20\%) and HPX (14\%) fetuses compared with their respective controls $(P<0.05)$. Food intake was similar regardless of treatment. Water intake was similar among NMX, HPX, and LNIL-treated groups. However, NAC reduced water intake in NMX but not HPX animals.

\section{LNIL Inhibits cGMP Levels in HPX Fetal Hearts}

Chronic hypoxia increased cGMP levels (pmoles/mg tissue) in fetal cardiac ventricles by $148 \%(0.0033 \pm 0.0007$ vs. $0.0082 \pm$ 0.0008 ; NMX $(n=5)$ vs. HPX $(n=5), P<0.05)$. LNIL administration in HPX animals reduced cGMP levels (0.0044 \pm 0.0013 ; HPX + LNIL $(n=6), P<0.05)$ to those of the untreated NMX controls. cGMP levels of NMX and NMX plus LNIL treatment were similar $(0.0026 \pm 0.00055 ; \mathrm{NMX}+\mathrm{LNIL}, n=5)$.

\section{Fetal Hypoxia Increases Lipid Peroxidation in Fetal Hearts}

Chronic hypoxia increased fetal cardiac malondialdehyde (nmol/ mg protein) by $42 \%$ compared with NMX controls $(1.16 \pm 0.07$ vs. $1.72 \pm 0.17$; $\operatorname{NMX}(n=5)$ vs. $\operatorname{HPX}, n=4$; Figure 1$)$. Maternal administration of LNIL abolished the hypoxia-induced increase in malondialdehyde $(1.21 \pm 0.12 ; \mathrm{HPX}+\mathrm{LNIL}, n=4 ; P<0.05)$ compared with hypoxia alone. Similarly, maternal NAC prevented the hypoxia-induced increase in fetal cardiac malondialdehyde levels $(1.03 \pm 0.04 ; \mathrm{HPX}+\mathrm{NAC}, n=3 ; P<0.05)$.

\section{Fetal Hypoxia Increases 3-NT}

3-NT was detected by immunohistochemistry of intact cardiac ventricles from hearts of NMX and HPX animals treated with and without LNIL (Figure 2a). Figure 2 shows positive brown immunostaining of 3-NT in cardiac sections of fetal hearts. The upper panels show representative images of cardiac ventricles from the four treatment groups. Positive immunostaining for 3-NT was greater in HPX fetal cardiac ventricles compared with NMX controls. LNIL administration during HPX reduced 3-NT staining to levels of NMX and had no effect on 3-NT staining alone. Figure $2 \mathrm{~b}$ shows western blot analysis of $3-\mathrm{NT}$ protein expression of isolated fetal cardiomyocytes obtained from hearts from each treatment group. Fetal hypoxia $(n=4)$ increased 3-NT expression by $82.9 \%$ compared with NMX controls $(n=4)(P<0.05)$. Maternal LNIL (HPX + LNIL, $n=4)$ significantly inhibited the hypoxia-induced increase in 3-NT and had no significant effect in cardiomyocytes of NMX hearts $(\mathrm{NMX}+\mathrm{LNIL}, n=4)$. Because of differences in band density of $\beta$-actin in different blots, relative density values (3-NT/ $\beta$-actin) were compared with their respective controls within each blot

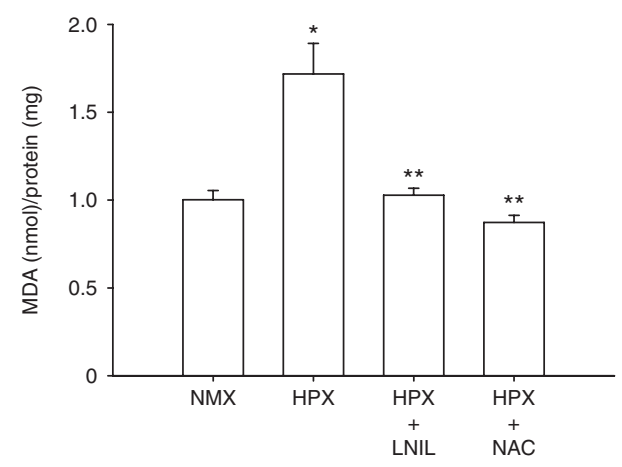

Figure 1. Malondialdehyde (MDA) levels of normoxic (NMX) and hypoxic (HPX) fetal guinea pig cardiac ventricles treated with and without L-N6(1-iminoethyl)-lysine (LNIL) and $N$-acetylcysteine (NAC). Values are expressed as mean \pm SEM. ${ }^{*} P<0.05$ vs. NMX; ${ }^{* *} P<0.05$ vs. HPX.

Table 1. Fetal body weights, organ weights, relative weights, and food and water intake

\begin{tabular}{|c|c|c|c|c|c|c|}
\hline & NMX & HPX & NMX + LNIL & HPX + LNIL & $\mathrm{NMX}+\mathrm{NAC}$ & $\mathrm{HPX}+\mathrm{NAC}$ \\
\hline BW (g) & $85.7(4.9)$ & $69.2(2.6)^{*}$ & $69.8(3.5)^{*}$ & $65.9(2.4)$ & $68.6(2.9)^{*}$ & $59.7(1.6)^{* *}$ \\
\hline Placenta (g) & $4.73(0.21)$ & $4.77(0.19)$ & $3.97(0.15)$ & $4.83(0.25)$ & $3.64(0.17)$ & $3.68(0.10)$ \\
\hline Brain (g) & $2.62(0.05)$ & $2.41(0.03)$ & $2.45(0.06)$ & $2.37(0.03)$ & $2.49(0.05)$ & $2.35(0.02)$ \\
\hline Liver (g) & $4.35(0.26)$ & $3.45(0.18)$ & $3.30(0.25)$ & $3.33(0.19)$ & $4.00(0.23)$ & $3.20(0.16)$ \\
\hline Heart/BW $(\mathrm{g} / \mathrm{g})$ & $0.0053(0.0001)$ & $0.0062(0.0002)^{*}$ & $0.0057(0.0001)$ & $0.0060(0.0002)$ & $0.0056(0.0002)$ & $0.0060(0.0002)$ \\
\hline Brain/BW (g/g) & $0.0320(0.0008)$ & $0.0362(0.0010)^{*}$ & $0.0363(0.0018)$ & $0.0367(0.0010)$ & $0.0370(0.0014)$ & $0.0400(0.0009)$ \\
\hline Liver/BW (g/g) & $0.052(0.001)$ & $0.051(0.002)$ & $0.047(0.002)$ & $0.050(0.002)$ & $0.058(0.001)$ & $0.053(0.002)$ \\
\hline Food $(g / d)$ & $38.0(2.5)$ & $42.4(2.2)$ & $39.0(3.0)$ & $52.9(6.7)$ & $32.5(4.0)$ & $39.4(4.2)$ \\
\hline Water $(\mathrm{ml} / \mathrm{d})$ & $73(4)$ & $118(25)$ & $88(10)$ & $135(38)$ & $46(5)^{*}$ & $68(7)$ \\
\hline
\end{tabular}

Values are expressed as mean (SEM). NMX, $n=25 ; \mathrm{HPX}, n=23 ; \mathrm{NMX}+\mathrm{LNIL}, n=20 ; \mathrm{HPX}+\mathrm{LNIL}, n=23 ; \mathrm{NMX}+\mathrm{NAC}, n=16 ; \mathrm{HPX}+\mathrm{NAC}, n=25$

BW, body weight; HPX, hypoxic; LNIL, L-N6-(1-iminoethyl)-lysine; NAC, N-acetylcysteine; NMX, normoxic.

Significant differences are indicated by ${ }^{*}$ (vs. NMX; $\left.P<0.05\right)$ and ${ }^{* *}($ vs. HPX; $P<0.05)$ 

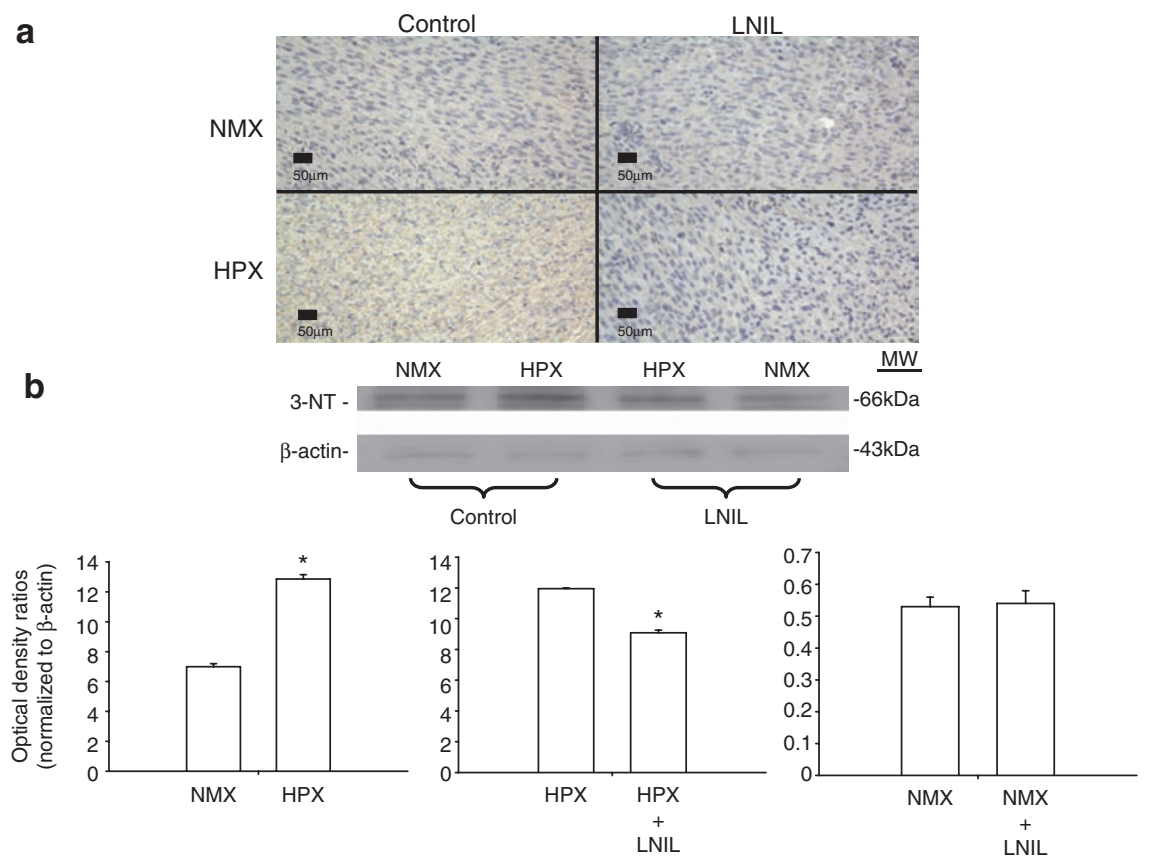

Figure 2. Immunohistochemistry of fetal heart ventricles (a) and western blot analysis of isolated cardiomyocytes (b) of 3-nitrotyrosine (3-NT) of normoxic (NMX) and hypoxic (HPX) fetal guinea pigs treated with and without (control) L-N6-(1-iminoethyl)-lysine (LNIL). Density values of each band were normalized to $\beta$-actin as a loading control and are reported as a ratio. Values are mean \pm SEM. ${ }^{*} P<0.05$.

and are shown in separate graphs. Student's $t$ test was performed for comparison between groups with a $P$ value of $<0.05$ for statistical significance.

\section{Fetal Hypoxia Increases MMP9 in Fetal Hearts}

Figure 3 shows MMP9 protein expression of fetal heart ventricles of NMX and HPX animals treated with and without LNIL. Each image shows a representative section of fetal heart ventricles from the four treatment groups immunostained against MMP9. The lower graph shows the average stain density of hearts for each treatment group expressed as density per standardized viewing area. Fetal hypoxia $(n=5)$ significantly increased immunostaining of MMP9 in fetal cardiac ventricles compared with NMX controls $(n=5)$. Furthermore, maternal treatment with LNIL (HPX + LNIL, $n=4)$ significantly inhibited the MMP9 expression in fetal hearts exposed to hypoxia. LNIL (NMX + LNIL, $n$ =4) had no effect on MMP9 expression in NMX controls. In a separate group of animals (Figure 4), maternal NAC (HPX + NAC, $n=6$ ) similarly inhibited the hypoxia-induced increase in MMP9 expression. NAC (NMX + NAC, $n=6$ ) had no effect on MMP9 expression in NMX controls.

\section{Fetal Hypoxia Increases Collagen Levels in Fetal Hearts}

Collagen was identified in intact fetal cardiac ventricles and quantified using Sirius Red staining (Figure $5 \mathrm{a}-\mathrm{f}$ ). Images are representative of NMX (a), HPX (b), NMX + LNIL (c), HPX + LNIL (d), NMX + NAC (e), and HPX + NAC (f). Fetal hypoxia $(n=5)$ significantly increased $(P<0.05)$ stain density in fetal cardiac ventricles compared with NMX controls $(n=4)$. Maternal administration of either LNIL (HPX + LNIL, $n=5$ ) or NAC (HPX + NAC, $n=5)$ inhibited collagen staining in HPX

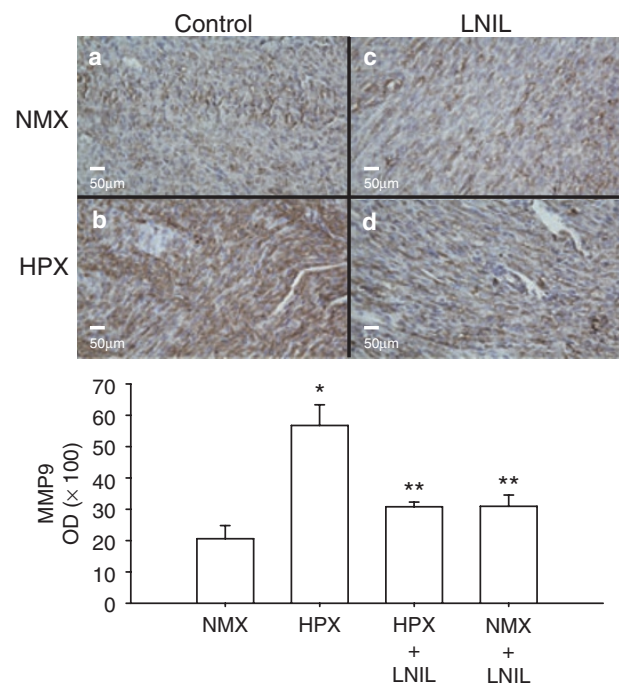

Figure 3. Immunohistochemistry (upper figures) and quantification of matrix metalloproteinase 9 (MMP9) in normoxic (NMX) (a,c) and hypoxic $(\mathrm{HPX})(\mathbf{b}, \mathbf{d})$ fetal guinea pig heart ventricles treated with and without (control) L-N6-(1-iminoethyl)-lysine (LNIL). Figures (original magnification $\times 200$ ) show MMP9 expression (brown stain) and nuclei of cardiomyocytes (blue stain). Values are mean \pm SEM. ${ }^{*} P<0.05$ vs. NMX; ${ }^{* *} P<0.05$ vs. HPX.

fetal hearts to levels similar to those in NMX controls $(P<0.05)$. Treatment with either LNIL (NMX + LNIL, $n=4$; Figure $5 \mathrm{c}$ ) or NAC (NMX + NAC, $n=4$; Figure $5 \mathrm{f}$ ) alone had no effect on NMX hearts.

\section{DISCUSSION}

This study indicates that chronic hypoxia increases peroxynitrite in fetal guinea pig hearts through iNOS-derived NO synthesis. 

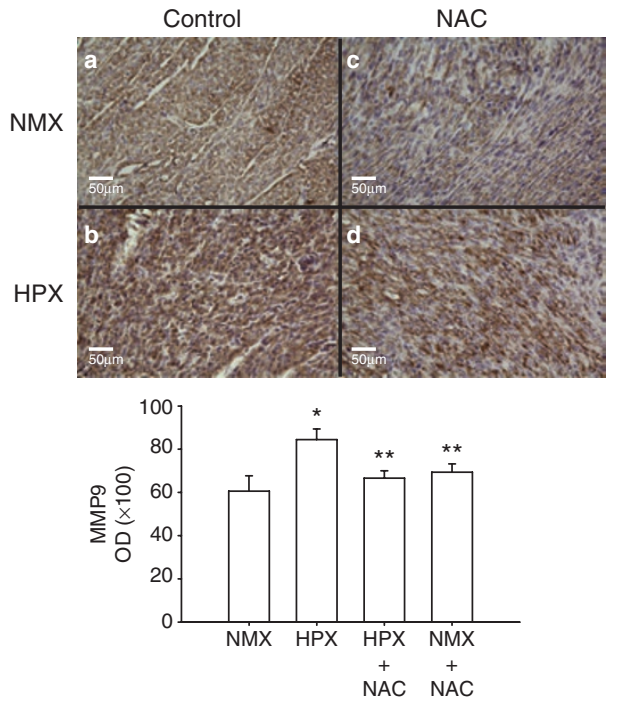

Figure 4. Immunohistochemistry (upper figures) and quantification of matrix metalloproteinase 9 (MMP9) in normoxic (NMX) $(\mathbf{a}, \mathbf{c})$ and hypoxic (HPX) (b,d) fetal guinea pig heart ventricles treated with and without (control) $\mathrm{N}$-acetylcysteine $(\mathrm{NAC})$. Figures (original magnification $\times 200$ ) show MMP9 expression (brown stain) and nuclei of cardiomyocytes (blue stain). Values are mean \pm SEM. ${ }^{*} P<0.05$ vs. NMX; $P<0.05$ vs. HPX.
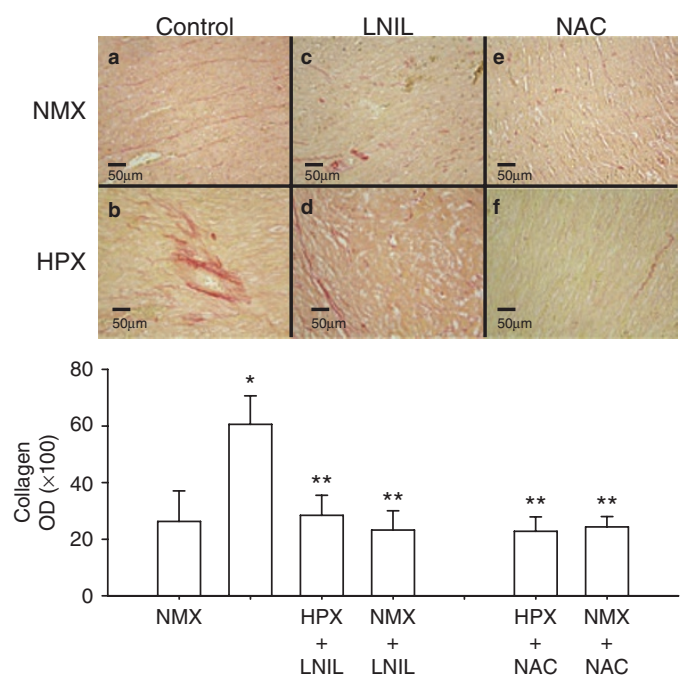

Figure 5. Sirius red staining (upper figures) and quantification of collagen fibers in normoxic (NMX) $(\mathbf{a}, \mathbf{c}, \mathbf{e})$ and hypoxic (HPX) $(\mathbf{b}, \mathbf{d}, \mathbf{f})$ fetal guinea pig heart ventricles from animals treated with and without (control) L-N6-(1-iminoethyl)-lysine (LNIL) or N-acetylcysteine (NAC). Figures (original magnification $\times 200$ ) show collagen fibers (red stain) and cardiomyocytes (yellow background). Values are mean \pm SEM. ${ }^{*} P<0.05$ vs. NMX; ${ }^{* *} P<0.05$ vs. HPX.

Significant increases in 3-NT protein levels were measured in HPX fetal hearts but were inhibited in the presence of LNIL. The hypoxia-induced increase in MMP9 expression, as evidenced by increased immunostaining of fetal cardiac ventricles, was decreased by both LNIL and NAC used alone. Fetal hypoxia also increased collagen accumulation in fetal hearts, which was reversed by both LNIL and NAC. The pattern of inhibition of 3-NT, MMP9, and collagen by LNIL and NAC provides evidence that peroxynitrite generation in chronically HPX fetal hearts plays an important role in modulating the ECM of the myocardium. Upregulation of MMP expression leading to modulation of the ECM in the fetus suggests that intrauterine hypoxia could be a precursor to increased risk of heart failure or other cardiac pathologies in the offspring (29-32).

\section{Maternal Hypoxia Induces Fetal Hypoxia}

Maternal hypoxia caused fetal growth restriction, a compensatory increase in placental growth, and pups that exhibited fetal heart- and brain-sparing effects $(33,34)$. We previously reported that maternal hypoxia increases red blood cell content and reticulocyte number in fetal guinea pig blood (2) and induces local tissue hypoxia of fetal hearts as evidenced by increased hypoxia-inducible factor- $1 \alpha$ mRNA and protein levels in HPX fetal guinea pig cardiac ventricles (1). In addition, maternal hypoxia increases fetal cardiac iNOS mRNA/protein levels, tissue $\mathrm{NO}_{2}^{-} / \mathrm{NO}_{3}^{-}$content (1), and cGMP levels. The effect of LNIL on both $\mathrm{NO}_{x}$ production and cGMP levels is consistent with inhibition of iNOSderived NO synthesis (1) because hypoxia, under identical conditions of study, decreases fetal guinea pig cardiac eNOS mRNA/protein expression (3) and has no effect on neuronal NOS expression (1) in fetal guinea pig hearts. Both LNIL and NAC restricted fetal growth by mechanisms that remain unclear.

\section{Fetal Hypoxia Increases Lipid Peroxidation}

Lipid peroxidation is a result of oxidation of plasma membrane phospholipids (26). Hypoxia has been shown to generate oxidizing species in cardiac tissue through several mechanisms, including upregulation of nicotinamide adenine dinucleotide phosphate oxidase (35) and/or inhibition of mitochondrial function (35). Although each mechanism may generate superoxide anions $\left(\mathrm{O}_{2}^{-}\right)$, the mechanisms that contribute to increased lipid peroxidation in HPX fetal hearts are not known. Although $\mathrm{O}_{2}^{-}$levels were not measured in the current study, the evidence that both LNIL and NAC inhibit lipid peroxidation is consistent with oxidative stress, associated with generation of $\mathrm{NO}$ and $\mathrm{O}_{2}^{-}$, respectively. We propose that the increase in lipid peroxidation in HPX fetal hearts is likely mediated through increased peroxynitrite generation $(36,37)$.

\section{Fetal Hypoxia Generates Peroxynitrite}

Peroxynitrite is generated by the interaction of $\mathrm{NO}$ and $\mathrm{O}_{2}^{-}$ $(27,36,37)$, and it selectively nitrates tyrosine residues to form 3-NT (27). Cardiac proteins identified to be selectively nitrated include those responsible for energy production and metabolism and structural integrity of the cells (38). Fetal hypoxia increased 3-NT expression in both cardiomyocytes and the fetal myocardium. The inhibitory effect of LNIL on protein expression, confirmed by both western blot analysis and immunostaining, supports an important biological role of iNOS-derived NO in generating peroxynitrite in the myocardium of fetal guinea pig hearts. 


\section{Effect of Peroxynitrite on MMP9 Expression}

Peroxynitrite has been reported to increase MMP9 expression in the adult myocardium (37). Furthermore, the increase in MMP9 and/or MMP2 expression has been shown to contribute to an increase in cardiac fibrosis in adult hearts $(39,40)$. The current study indicates that both iNOS-derived NO and reactive oxygen species are sufficient to induce MMPs because each inhibitor (i.e., LNIL and NAC) was capable of inhibiting MMP9 expression individually.

Peroxynitrite has been shown to be a highly reactive molecule that has multiple downstream actions such as transcription of genes, oxidation and nitration of proteins, DNA damage, and lipid peroxidation (16). Peroxynitrite has also been shown to increase MMP9 activity by autolytic cleavage of the cysteine thiol group and increase MMP9 expression by transcriptional regulation through nuclear factor-kappa B and activator protein-1 (19). We are not aware of any evidence that NO can directly activate MMP9 and/or transcriptionally regulate MMP9 expression. Rather, we propose that the biological action of NO on MMP9 activation is mediated through peroxynitrite.

\section{Fetal Hypoxemia Increases Collagen Accumulation}

MMPs are key regulatory proteins in the modulation of collagen in the ECM, with MMP9 having an important role in cardiac tissue (20). Fetal hypoxia, under identical conditions of the current study, increases MMP9 protein levels but not MMP2 protein expression in fetal guinea pig hearts (3), and the current study suggests that peroxynitrite formation may contribute to this HPX response. The increase in MMP9 levels parallels collagen accumulation. Although MMP9 can degrade collagen via its gelatinolytic activity, we measured a paradoxical increase in collagen levels. This may occur if chronic exposure to hypoxia disrupts the balance between collagen synthesis and degradation as a result of time-dependent generation of matrikines (subfragments of collagen degradation), which stimulates further collagen synthesis $(39,40)$. We hypothesize that chronic hypoxia is sufficient to generate collagen accumulation in fetal hearts with increased MMP activation, although the causal relationship remains unknown. Regardless, both NAC and LNIL inhibited the increase in collagen levels generated by hypoxia, and this parallels the inhibitory effects of drug treatment on MMP9 levels in fetal hearts. Thus, we propose that peroxynitrite is a precursor to increased MMP9 levels and, subsequently, collagen accumulation in HPX fetal guinea pig hearts.

This study provides the first evidence that chronic intrauterine hypoxia generates conditions in fetal hearts that are capable of producing peroxynitrite in cardiomyocytes in vivo, which may induce MMP expression and contribute to cardiac remodeling through collagen accumulation. Furthermore, iNOS-derived NO and oxidative stress are important factors that initiate activation of MMPs such as MMP9. The combination of both upregulation of MMP9 and collagen accumulation that persists after $2 \mathrm{wk}$ of hypoxia exposure suggests that modulation of collagen synthesis may contribute to cardiac restructuring in the HPX fetal heart. Identification of the specific cellular factors contributing to the mechanism associated with cardiac remodeling in the fetus is important for developing therapeutic approaches that minimize the risk of cardiovascular diseases associated with intrauterine growth restriction.

\section{METHODS}

\section{Animal Model}

Pregnant Hartley guinea pigs were placed under either NMX (21\% $\left.\mathrm{O}_{2}\right)$ or HPX $\left(10.5 \% \mathrm{O}_{2}\right)$ conditions throughout the pregnancy for 14 $\mathrm{d}$ before term (term $=65 \mathrm{~d})(1-3)$. At near-term $(63 \mathrm{~d})$, pregnant sows were anesthetized (ketamine, $80 \mathrm{mg} / \mathrm{kg}$; xylazine, $1 \mathrm{mg} / \mathrm{kg}$ ), and fetuses were removed by means of hysterotomy. Fetal body and organ weights were measured. Fetal hearts were excised and ventricles were either frozen in liquid $\mathrm{N}_{2}$ and stored at $-80^{\circ} \mathrm{C}$ or fixed for immunohistochemistry. These methods were approved by the University of Maryland Animal Care Committee.

\section{Drug Treatment}

To test whether chronic hypoxia induces peroxynitrite formation through an iNOS-mediated pathway, both NMX and HPX animals were treated with LNIL, a selective iNOS inhibitor $(1,12,25)$, administered in the drinking water $(1-2 \mathrm{mg} / \mathrm{kg} / \mathrm{d})$ for $10 \mathrm{~d}, 4 \mathrm{~d}$ after being placed in the HPX chamber (1). In a separate group, pregnant sows were treated with NAC $(500 \mathrm{mg} / \mathrm{kg} / \mathrm{d})$ administered in the drinking water using the same protocol for LNIL. Both food $(\mathrm{g} / \mathrm{d})$ and water $(\mathrm{ml} / \mathrm{d})$ intake rates were measured throughout the duration of treatment.

\section{Effect of LNIL on Fetal Cardiac Cyclic Guanosine 59-Monophosphate Levels}

Prenatal treatment of pregnant sows with LNIL has been shown to significantly inhibit fetal cardiac NO synthesis as measured by fetal cardiac $\mathrm{NO}_{2}{ }^{-} / \mathrm{NO}_{3}^{-}$levels in hearts exhibiting upregulation of iNOS mRNA/protein expression (1). In addition, fetal cardiac cyclic guanosine 59-monophosphate (cGMP) was measured as a second messenger to NO synthesis with and without LNIL to confirm its inhibitory effect on NO synthesis. Fetal hearts were excised from NMX and HPX animals treated with and without LNIL, and frozen tissues were assayed for cGMP (pmoles/mg tissue) using an enzyme immunoassay (Assay Designs, Enzo Life Sciences, Plymouth Meeting, PA).

\section{Quantification of Fetal Cardiac Lipid Peroxidation}

Plasma membrane phospholipids are targeted molecules of oxidative stress (26), and malondialdehyde is measured as an index of lipid peroxidation (26). Frozen ventricles of fetal hearts from NMX and HPX guinea pigs treated with and without LNIL or NAC were used. Malondialdehyde was assayed using a thiobarbituric acid reactive substances assay (Cayman Chemical, Ann Arbor, MI), measured in triplicate, and normalized to milligram protein of each sample. Protein concentration was determined by Bradford protein assay (Bio-Rad Laboratories, Hercules, CA).

\section{Protein Quantification of 3-NT of Isolated Cardiomyocytes}

Peroxynitrite is a cytotoxic molecule that nitrates tyrosine residues and forms 3-NT (27). Protein level of 3-NT was quantified using western blot analysis of isolated fetal cardiomyocytes from hearts of NMX and HPX animals treated with and without LNIL.

Fetal cardiomyocyte preparation. Fetal hearts were excised and mounted through the aorta onto a Radnoti heart perfusion apparatus $\left(37^{\circ} \mathrm{C}\right)$, and cardiomyocytes were isolated (28). In brief, hearts were perfused for $5 \mathrm{~min}$ each with calcium-free Tyrodes buffer $\left(95 \% \mathrm{O}_{2} / 5 \% \mathrm{CO}_{2}\right)(140 \mathrm{mM} \mathrm{NaCl}, 5 \mathrm{mM} \mathrm{KCl}, 10 \mathrm{mM} \mathrm{N}-2$ hydroxyethylpiperazine- $\mathrm{N9}$-2-ethanesufonic acid, $10 \mathrm{mM}$ glucose, and $\left.1 \mathrm{mM} \mathrm{MgCl}_{2} ; \mathrm{pH} 7.35\right)$ at $37^{\circ} \mathrm{C}$, followed by a calcium-free Tyrodes buffer containing collagenase type II $(160 \mathrm{U} / \mathrm{ml})$, protease (Sigma Type XIV, $0.78 \mathrm{U} / \mathrm{ml})$, and bovine serum albumin $(1 \mathrm{mg} /$ 
$\mathrm{ml}$ ), and subsequently with Kraftbruhe solution $(30 \mathrm{mM} \mathrm{KCl}, 10 \mathrm{mM}$ $\mathrm{N}$-2-hydroxyethylpiperazine-N9-2-ethanesufonic acid, $10 \mathrm{mM}$ glucose, $74 \mathrm{mM}$ K-glutamate, $20 \mathrm{mM}$ taurine, $1.5 \mathrm{mM} \mathrm{MgSO}_{4}, 0.5 \mathrm{mM}$ ethyleneglycol-bis(baminoethylether)- $N, N 9$-tetraacetic acid, and $30 \mathrm{mM} \mathrm{KH} \mathrm{PO}_{4} ; \mathrm{pH}$ 7.37). Cells released from the digested hearts were collected into Kraftebruhe buffer and passed through $150-\mu \mathrm{m}$ nylon mesh to remove cellular debris. The suspension was centrifuged at $200 \mathrm{~g}(5 \mathrm{~min})$, washed, and resuspended in fresh buffer. Aliquots were centrifuged $(17,000 g)$, supernatant was discarded, and pellets were frozen at $-80^{\circ} \mathrm{C}$.

Western blot of 3-NT. Protein levels of 3-NT from isolated fetal cardiomyocytes of hearts from NMX and HPX guinea pigs treated with and without LNIL were quantified using western blot analysis (1). Frozen isolated fetal cardiomyocyte preparations were homogenized in $1 \times$ lysis buffer (cat. no. 20-188, Upstate Biotechnology, Billerica, MA), incubated on ice for $4 \mathrm{~h}$, and centrifuged at $1,000 \mathrm{~g}$ $\left(4{ }^{\circ} \mathrm{C} / 10 \mathrm{~min}\right)$. Protein concentrations were quantified by Bradford protein assay (Bio-Rad Laboratories). Equal amounts of protein $(20 \mu \mathrm{g})$ were loaded onto $7.5 \%$ Tris/glycine polyacrylamide gels and separated by gel electrophoresis. Proteins were transferred to Immun-Blot poly(vinylidene fluoride) membranes (Bio-Rad Laboratories), blocked for $2 \mathrm{~h}$, and probed with rabbit polyclonal antibody specific for 3-NT (1:1,000; Millipore, Billerica, MA) overnight at $4^{\circ} \mathrm{C}$, followed by a secondary IgG antibody $(1: 10,000)$. Protein bands were detected by enhanced chemiluminescence Western Blotting Analysis System (Perkin Elmer, Waltham, MA). Positive controls were used to identify selected proteins nitrated by peroxynitrite (e.g., 215, 66, 32, 16 kDa molecular weight). In guinea pig cardiomyocytes, protein bands of $66 \mathrm{kDa}$ were the only bands able to be detected by the anti-nitrotyrosine antibody (cat. no. 06-284, Millipore). Bands at $215 \mathrm{kDa}$ were not visible, and those at 16 and $32 \mathrm{kDa}$ were too faint to quantify. Although this may indicate selective nitration of specific proteins in the fetal heart, their identity is difficult to confirm simply on the basis of molecular weight. Bands were quantified by densitometry and normalized to $\beta$-actin as a loading control for each sample.

\section{Immunohistochemistry of 3-NT and MMP9}

Fetal hearts were excised and fixed in 10\% formalin (Sigma, St Louis, MO) for immunohistochemistry of 3-NT and MMP9. Hearts were dehydrated through increasing ethanol concentrations, paraffin embedded, and sectioned at $5 \mu \mathrm{m}$. Heart sections were deparaffinized and rehydrated through decreasing ethanol concentrations, and sections of each group were immunostained. Each of the sections was boiled in sodium citrate buffer $(\mathrm{pH} 6)$, treated with $0.3 \%$ $\mathrm{H}_{2} \mathrm{O}_{2}$, blocked with buffer containing normal goat serum (4\%), and incubated separately with anti-3-NT (1:1,000, Millipore) and antiMMP9 (1:50, Millipore) overnight at $4{ }^{\circ} \mathrm{C}$. Sections were subsequently incubated with biotinylated goat anti-rabbit secondary antibody (1:10,000; Vector Laboratories, Burlingame, CA). Avidin-biotin complex reagent (Vector Laboratories) was used in combination with the peroxide substrate solution composed of $10 \mathrm{ml}$ Tris buffer, $2 \mathrm{mg}$ 3,3'-diaminobenzidine tetrahydrochloride dihydrate, and $3 \% \mathrm{H}_{2} \mathrm{O}_{2}$. Negative controls were generated in the absence of primary antibody.

\section{Sirius Red Staining of Collagen}

Collagen fibers of fetal heart sections were visualized with Sirius Red stain. Paraffin-embedded fetal heart sections $(5 \mu \mathrm{m})$ were deparaffinized, rehydrated, and stained in $0.1 \%$ Sirius Red in saturated picric acid for $1 \mathrm{~h}$. Sections were rinsed two times with $0.5 \%$ acetic acid for $5 \mathrm{~min}$, dehydrated in three changes of $100 \%$ ethanol for $5 \mathrm{~min}$, and coverslipped for imaging using bright-field microscopy.

\section{Statistics}

Results are expressed as mean \pm SEM. Comparisons between groups were made using two-way ANOVA with hypoxia and drug treatment as independent variables. If mean values were found to be significantly different $(P<0.05)$, a Student-Newman-Keuls post hoc test was applied to analyze the differences between treatments. A single fetus was obtained from each litter representing each of the four treatment groups. A $P$ value of $<0.05$ indicates statistical significance between groups ( $n$ values $=$ number of fetuses). Positive staining was quantified using IPlab imaging software (Scanalytics, Fairfax, VA), a Nikon Eclipse E1000 microscope (Melville, NY), and a QImaging QICAM FAST 1394 camera (Surrey, British Columbia, Canada). The optical density of the brown (3,3'-diaminobenzidine tetrahydrochloride dihydrate) or red (Sirius Red) stain was quantified and normalized per standard area of each section. Six randomly chosen views of each section from a single animal were selected, measured as optical density for a given area, and averaged.

\section{STATEMENT OF FINANCIAL SUPPORT}

The project described was supported in part by NIH grants R01HL 49999 (L.P.T.) and F31HL 90044 (L.C.E.), from the National Heart, Lung, and Blood Institute. The content is solely the responsibility of the authors and does not necessarily represent the official view of the National Heart, Lung, and Blood Institute or the National Institutes of Health.

\section{REFERENCES}

1. Thompson L, Dong Y, Evans L. Chronic hypoxia increases inducible NOSderived nitric oxide in fetal guinea pig hearts. Pediatr Res 2009;65:188-92.

2. Thompson LP, Dong Y. Chronic hypoxia decreases endothelial nitric oxide synthase protein expression in fetal guinea pig hearts. J Soc Gynecol Investig 2005;12:388-95.

3. Oh C, Dong Y, Liu H, Thompson LP. Intrauterine hypoxia upregulates proinflammatory cytokines and matrix metalloproteinases in heart guinea pig hearts. Am J Obstet Gyncol 2008;199:78.e1-78.e6.

4. Zhang L. Prenatal hypoxia and cardiac programming. J Soc Gynecol Investig 2005;12:2-13.

5. Morrison JL, Botting KJ, Dyer JL, Williams SJ, Thornburg KL, McMillen IC. Restriction of placental function alters heart development in the sheep fetus. Am J Physiol Regul Integr Comp Physiol 2007;293: R306-13.

6. Camm EJ, Hansell JA, Kane AD, et al. Partial contributions of developmental hypoxia and undernutrition to prenatal alterations in somatic growth and cardiovascular structure and function. Am J Obstet Gynecol 2010;203:495.e24-34.

7. Kamitomo M, Onishi J, Gutierrez I, Stiffel VM, Gilbert RD. Effects of long-term hypoxia and development on cardiac contractile proteins in fetal and adult sheep. J Soc Gynecol Investig 2002;9:335-41.

8. Myatt L. Placental adaptive responses and fetal programming. J Physiol (Lond) 2006;572(Pt 1):25-30.

9. Pringle KG, Kind KL, Sferruzzi-Perri AN, Thompson JG, Roberts CT. Beyond oxygen: complex regulation and activity of hypoxia inducible factors in pregnancy. Hum Reprod Update 2010;16:415-31.

10. Mascio CE, Olison AK, Ralphe JC, Tomanek RJ, Scholz TD, Segar JL. Myocardial vascular and metabolic adaptations in chronically anemic fetal sheep. Am J Physiol Regul Integr Comp Physiol 2005;289:R1736-45.

11. Gagnon R. Placental insufficiency and its consequences. Eur J Obstet Gynecol Reprod Biol 2003;110:Suppl 1:S99-107.

12. Dong Y, Yu Z, Sun Y, et al. Chronic fetal hypoxia produces selective brain injury associated with altered nitric oxide synthases. Am J Obstet Gynecol 2011;204:254.e16-254.e28.

13. Patterson AJ, Chen M, Xue Q, Xiao D, Zhang L. Chronic prenatal hypoxia induces epigenetic programming of $\mathrm{PKC}\{$ epsilon\} gene repression in rat hearts. Circ Res 2010;107:365-73.

14. Knowles RG, Moncada S. Nitric oxide synthases in mammals. Biochem J 1994;298 (Pt 2):249-58.

15. Fantel AG, Mackler B, Stamps LD, Tran TT, Person RE. Reactive oxygen species and DNA oxidation in fetal rat tissues. Free Radic Biol Med 1998;25:95-103.

16. Pacher P, Beckman JS, Liaudet L. Nitric oxide and peroxynitrite in health and disease. Physiol Rev 2007;87:315-424. 
17. Ferdinandy P, Danial H, Ambrus I, Rothery RA, Schulz R. Peroxynitrite is a major contributor to cytokine-induced myocardial contractile failure. Circ Res 2000;87:241-7.

18. Armstrong PW, Moe GW, Howard RJ, Grima EA, Cruz TF. Structural remodelling in heart failure: gelatinase induction. Can J Cardiol 1994;10:214-20.

19. Spinale FG. Myocardial matrix remodeling and the matrix metalloproteinases: influence on cardiac form and function. Physiol Rev 2007;87:1285-342.

20. D'Armiento J. Matrix metalloproteinase disruption of the extracellular matrix and cardiac dysfunction. Trends Cardiovasc Med 2002;12:97-101.

21. Frantz S, Hu K, Bayer B, et al. Absence of NF-kappaB subunit p50 improves heart failure after myocardial infarction. FASEB J 2006;20:1918-20.

22. Creemers EE, Cleutjens JP, Smits JF, Daemen MJ. Matrix metalloproteinase inhibition after myocardial infarction: a new approach to prevent heart failure? Circ Res 2001;89:201-10.

23. López B, González A, Díez J. Role of matrix metalloproteinases in hypertension-associated cardiac fibrosis. Curr Opin Nephrol Hypertens 2004;13:197-204.

24. Li YY, McTiernan CF, Feldman AM. Interplay of matrix metalloproteinases, tissue inhibitors of metalloproteinases and their regulators in cardiac matrix remodeling. Cardiovasc Res 2000;46:214-24.

25. Moore WM, Webber RK, Jerome GM, Tjoeng FS, Misko TP, Currie MG. L-N6-(1-iminoethyl)lysine: a selective inhibitor of inducible nitric oxide synthase. J Med Chem 1994;37:3886-8.

26. Dawn-Linsley M, Ekinci FJ, Ortiz D, Rogers E, Shea TB. Monitoring thiobarbituric acid-reactive substances (TBARs) as an assay for oxidative damage in neuronal cultures and central nervous system. J Neurosci Methods 2005;141:219-22.

27. Ischiropoulos $\mathrm{H}$. Biological selectivity and functional aspects of protein tyrosine nitration. Biochem Biophys Res Commun 2003;305:776-83.

28. Giraud GD, Louey S, Jonker S, Schultz J, Thornburg KL. Cortisol stimulates cell cycle activity in the cardiomyocyte of the sheep fetus. Endocrinology 2006;147:3643-9.

29. Xu Y, Williams SJ, O'Brien D, Davidge ST. Hypoxia or nutrient restriction during pregnancy in rats leads to progressive cardiac remodeling and impairs postischemic recovery in adult male offspring. FASEB J 2006;20:1251-3.
30. Li G, Xiao Y, Estrella JL, Ducsay CA, Gilbert RD, Zhang L. Effect of fetal hypoxia on heart susceptibility to ischemia and reperfusion injury in the adult rat. J Soc Gynecol Investig 2003;10:265-74.

31. Broberg CS, Giraud GD, Schultz JM, Thornburg KL, Hohimer AR, Davis LE. Fetal anemia leads to augmented contractile response to hypoxic stress in adulthood. Am J Physiol Regul Integr Comp Physiol 2003;285: R649-55.

32. Xue Q, Zhang L. Prenatal hypoxia causes a sex-dependent increase in heart susceptibility to ischemia and reperfusion injury in adult male offspring: role of protein kinase C epsilon. J Pharmacol Exp Ther 2009;330:624-32.

33. Dubiel M, Gunnarsson GO, Gudmundsson S. Blood redistribution in the fetal brain during chronic hypoxia. Ultrasound Obstet Gynecol 2002;20:117-21.

34. Regnault TR, de Vrijer B, Galan HL, Wilkening RB, Battaglia FC, Meschia G. Development and mechanisms of fetal hypoxia in severe fetal growth restriction. Placenta 2007;28:714-23.

35. Raddatz E, Thomas AC, Sarre A, Benathan M. Differential contribution of mitochondria, NADPH oxidases, and glycolysis to region-specific oxidant stress in the anoxic-reoxygenated embryonic heart. Am J Physiol Heart Circ Physiol 2011;300:H820-35.

36. Zhang P, Xu X, Hu X, van Deel ED, Zhu G, Chen Y. Inducible nitric oxide synthase deficiency protects the heart from systolic overloadinduced ventricular hypertrophy and congestive heart failure. Circ Res 2007;100:1089-98.

37. Mukhopadhyay P, Rajesh M, Bátkai S, et al. Role of superoxide, nitric oxide, and peroxynitrite in doxorubicin-induced cell death in vivo and in vitro. Am J Physiol Heart Circ Physiol 2009;296:H1466-83.

38. Kanski J, Behring A, Pelling J, Schöneich C. Proteomic identification of 3-nitrotyrosine-containing rat cardiac proteins: effects of biological aging. Am J Physiol Heart Circ Physiol 2005;288:H371-81.

39. Polyakova V, Miyagawa S, Szalay Z, Risteli J, Kostin S. Atrial extracellular matrix remodelling in patients with atrial fibrillation. J Cell Mol Med 2008;12:189-208.

40. Ichihara S, Noda A, Nagata K, et al. Pravastatin increases survival and suppresses an increase in myocardial matrix metalloproteinase activity in a rat model of heart failure. Cardiovasc Res 2006;69:726-35. 